\title{
Using federal funds futures contracts for monetary policy analysis*
}

\author{
Refet S. Gürkaynak \\ rgurkaynak@frb.gov \\ Division of Monetary Affairs \\ Board of Governors of the Federal Reserve System \\ Washington, DC 20551
}

J une 5,2005

\begin{abstract}
Federal funds futures are popular tools for calculating market-based monetary policy surprises. These surprises are usually thought of as the difference between expected and realized federal funds target rates at the current FOMC meeting. This paper demonstrates the use of federal funds futures contracts to measure how FOMC announcements lead to changes in expected interest rates after future FOMC meetings. Using several 'surprises' at different horizons, timing, level, and slope components of unanticipated policy actions are defined. These three components have differing effects on asset prices that are not captured by the contemporaneous surprise measure.
\end{abstract}

*The opinions expressed are those of the author and do not necessarily reflect the views of the Board of Governors or other members of its staff. I thank Brian Sack and Eric Swanson for many discussions on monetary policy surprises, and Ben Bernanke, Ken Kuttner, and Jonathan Wright for useful suggestions. Andrea Surratt provided outstanding research assistance. 


\section{Introduction}

Measuring the effects of monetary policy on asset prices is a tricky task. Both the policy tool, the federal funds rate, and other asset prices are jump variables, which makes it difficult to come up with reasonable identifying assumptions in monthly or quarterly analysis. Economists, at least since Cook and Hahn (1989), have been trying to overcome this hurdle by running eventstudy regressions using higher frequency (usually daily) data. Cook and Hahn had used the raw policy action as independent variable in their study. However, we expect asset prices to only react to the unanticipated policy action, which necessitates measuring the policy surprise.

To isolate policy surprises, calculating the unanticipated part of the policy action from market-based measures has recently become popular in the academic literature, federal funds futures being the most commonly employed securities for this purpose (see Kuttner, 2001, for an important early contribution). This literature focuses on calculating very short horizon surprises, most often the surprise associated with the funds rate expected to prevail until the next period, the next Federal Open Market Committee (FOMC) meeting. However, the FOMC may give different policy signals pertaining to longer horizons by the statement, or investors can infer different signals based on the state of the business cycle. A hawkish statement about future interest rate changes, for example, can counterweigh the effects of an easing surprise on expectations about funds rates after the next meeting. That is, a single FOMC policy announcement can contain different policy 'surprises' for different horizons. Papers that use changes in expectations at longer horizons to capture a relatively more permanent surprise, such as Bernanke and Kuttner (2005), use changes in expectations in a future month. But Federal Reserve's interest rate decisions are not made monthly. For example, a three month time period can span one or two FOMC meetings. 
As interest rates change almost exclusively at scheduled FOMC meetings, the natural horizon for thinking about interest rate changes is in terms of FOMC meetings. $^{1}$

This paper uses long-maturity federal funds futures contracts to extract policy expectations and surprises at horizons defined by future FOMC meetings. Since the FOMC schedule is known in advance, it is possible to use the contracts expiring in the months of future FOMC meetings to measure market-based expectations for these meetings and, of course, changes in these expectations (surprises at longer FOMC meeting horizons) due to FOMC announcements. The first part of the paper demonstrates the mechanics of these calculations.

In the second part of the paper the "surprises at FOMC meeting horizons" idea is put to work for an empirical application. Using the policy surprise for the current funds rate decision, and changes in expected funds rates after the next and the following FOMC meetings on the day of the current policy action, policy surprises can be decomposed into timing, level, and slope components. Level surprises are the relatively lasting changes in policy expectations, measured as the changes in expected rates after the next FOMC meeting. Timing surprises, on the other hand, are constructed to have no effect on the expected funds rates after the next meeting, while slope surprises are changes in expected rates after the second FOMC meeting that are over and above the level surprise.

Thinking about different types of monetary policy surprises and measuring monetary policy as a multi-dimensional process are novel. Hamilton and Jorda (2002) recognize the discrete nature of policy actions and differentiate between macroeconomic effects of an unanticipated policy change and a policy inaction when a policy change was expected. Using a factor model Gürkaynak, Sack, and Swanson (2005b) show that monetary policy is characterized by two factors rather than a single one and they identify the two dimensions of monetary policy

\footnotetext{
${ }^{1}$ Intermeeting policy actions were especially rare after 1994 .
} 
using a factor rotation. ${ }^{2}$

While measuring monetary policy surprises at different horizons from federal funds futures contracts is a general method, interpreting those surprises requires imposing some structure. The timing/level/slope decomposition proposed in this paper is one such structure and the empirical analysis shows that the three surprise components' effects on asset prices are consistent with their names. Timing has no effect on asset prices other than short-maturity yields, while level has a large effect on all asset prices. The conventional measure of policy surprises, the surprise to expected funds rates in the current intermeeting period, understates the effects of monetary policy on asset prices because this surprise measure is a combination of timing and level. The slope component is also estimated to have a significant effect on long-term yields.

\section{Federal funds futures contracts}

Federal funds futures are contracts with payouts at maturity based on the average effective federal funds rate during the month of expiration. These securities have been trading on the Chicago Board of Trade (CBOT) since late 1988. The value of the contract at expiration is $100-\bar{r}$, where $\bar{r}$ is the average effective federal funds rate over the expiry month. ${ }^{3}$ Contracts with expiration maturities out to two years are offered, but most of the trading takes place in contracts with expiry dates within six months.

Prices of these contracts are clearly related to expectations of target federal funds rates, which makes them useful for policy analysis. There are many other securities that have payouts tied to the funds rate in some way, such

\footnotetext{
${ }^{2}$ Craine and Martin (2004) also use a factor model to analyze the policy transmission mechanism, extending the heteroskedasticity based identification method of Rigobon and Sack (2002).

${ }^{3}$ In showing the mechanics of using federal funds futures to calculate monetary policy surprises below, it is assumed that effective funds rates are equal to target rates. This assumption simplifies notation and does not make a substantive difference.
} 
as commercial paper and eurodollar deposits; however, Gürkaynak, Sack, and Swanson (2002) show that for horizons up to six months investors' forecasts measured using the federal funds futures rates outperform all other marketbased measures in predicting actual future funds rates. This justifies using federal funds futures to gauge policy expectations as rational expectations would incorporate the best forecast.

Federal funds futures can be used to calculate levels and changes of interest rate expectations for any date within the maturity of the futures contracts. These contracts were introduced to the literature by Krueger and Kuttner (1996), Rudebusch (1998), Söderström (2001) and popularized by Kuttner (2001). Below, the implied rates from these securities' prices are employed to calculate market-based measures of the surprise associated with the current policy decision, and changes in expected rates after the next and further away FOMC meetings around the current meeting, as well as to generate marketbased measures of levels of expected interest rates for horizons encompassing a given number of FOMC meetings.

\section{$3 \quad$ Using federal funds futures contracts}

\subsection{Basics}

Calculating expectations and surprises from federal funds futures contracts requires introducing some notation first. In what follows, subscript $t$ denotes time, in days or at a higher frequency. For convenience, think of date " $t$ " as a policy date, so that changes in prices of federal funds futures on this day are due to FOMC actions. Policy date refers to dates of scheduled FOMC meetings (regardless of a policy change taking place or not) and dates of intermeeting 
policy actions. ${ }^{4}$ FOMC meetings are indexed by $j$, with $j=0$ the current meeting $j=1$ the next scheduled meeting, etc., and $i(j)$ denotes how many months away the $j^{\text {th }}$ FOMC is, starting with 0 for the current meeting. The rate implied by the federal funds futures contract is $f_{t}^{i(j)}$, for the contract expiring in $i(j)$ months. Finally, let $d_{j}$ denote the day of the $j^{\text {th }}$ FOMC meeting and $m_{j}$ the number of days in that month.

Having introduced the notation, it is also important to spell out a key assumption explicitly: throughout the paper it is assumed that on policy dates future intermeeting moves are seen as zero probability events. This assumption is reasonable given the infrequency and unexpectedness of intermeeting policy actions. ${ }^{5}$ It is required because the analysis below is carried out at FOMC meeting frequency using dates of future meetings and, of course, dates of future intermeeting moves are not known in advance.

A final note about the references to time periods in this paper are in order, for clarity. The federal funds futures prices are time series data. Frequency refers to the observation interval of this data. At each point in time, prices of all federal funds futures contracts currently trading are observed. These contracts cover different months, referred to as maturities, or expirations. Finally, at each point in time, looking ahead, investors think about what will happen to interest rates at different FOMC meeting horizons. "Horizon" refers to expectations about different points in time, but all of these expectations are formed today. Similarly, when the discussion is about changes in expectations (surprises) at different horizons, it should be clear that all these surprises take place today, on the day of the current FOMC meeting.

To use the futures contracts for monetary policy analysis we start with the

\footnotetext{
${ }^{4}$ Of course, with intraday data the policy date refers to the policy announcement time.

${ }^{5}$ Intermeeting policy actions took place relatively more often in the pre-1994 period. In the empirical part of this paper the post-1994 sample is used to check for robustness of the results.
} 
simplest case, constructing the surprise component of the current policy decision for the spot rate, and then extend the analysis to changes in expectations about future interest rates.

\subsection{Current policy surprise}

Calculating monetary policy surprises by using federal funds futures rates was brought to the forefront of policy analysis by Kuttner (2001). In this subsection we follow him to show the relationship between federal funds futures rates and the FOMC policy decision. On the day before the FOMC meeting the arbitrage-free price of the spot-month federal funds future contract will satisfy ${ }^{6}$

$$
f_{t-1}^{0}=\frac{d_{0}}{m_{0}} r_{-1}+\frac{m_{0}-d_{0}}{m_{0}} E_{t-1}\left(r_{0}\right)+\mu_{t-1}^{0},
$$

where $r_{-1}$ is the target federal funds rate prevailing before the meeting and $r_{0}$ is the target rate after the meeting. ${ }^{7}$ The quantity $\mu_{t-1}^{0}$ represents a termpremium for the spot-moth contract, which will be discussed later. Apart from the term premium, the spot month federal funds futures rate is equal to the expected average target rate over the month, given by the the weighted average of the two target rates. After the policy decision is known, at time $t$, the implied futures rate is

$$
f_{t}^{0}=\frac{d_{0}}{m_{0}} r_{-1}+\frac{m_{0}-d_{0}}{m_{0}} r_{0}+\mu_{t}^{0}
$$

Using equations (1) and (2), the unanticipated component of the monetary policy action, call it $e_{t}^{0}$, is given by

$$
e_{t}^{0} \equiv r_{0}-E_{t-1}\left(r_{0}\right)=\left[\left(f_{t}^{0}-f_{t-1}^{0}\right)-\left(\mu_{t}^{0}-\mu_{t-1}^{0}\right)\right] \frac{m_{0}}{m_{0}-d_{0}} .
$$

\footnotetext{
${ }^{6}$ See Gürkaynak, Sack, and Swanson (2002) for a derivation from first principles.

${ }^{7}$ Note again that we are assuming that effective funds rates are equal to the target rate. Otherwise $r_{-1}$ should be replaced by the average effective rate so far in the month.
} 
Note that the previous target rate (observed effective funds rates until the policy date) drops out due to the differencing. This is why assuming that effective funds rates are equal to the target rates is a simplifying assumption, as long as agents do not expect future effective rates to differ from target rates.

Backing out the policy surprise from futures prices requires making a rather weak assumption about the behavior of the term premium. Assuming that the high frequency change (the change around the policy action) in the term premium is negligible, the unanticipated policy action is

$$
e_{t}^{0}=\left(f_{t}^{0}-f_{t-1}^{0}\right) \frac{m_{0}}{m_{0}-d_{0}}
$$

which is the scaled change in the futures rate around the policy action. Scaling is necessary because the surprise is only relevant for the remaining part of the month. ${ }^{8}$

This measure of policy surprise, $e_{t}^{0}$, was referred to as the "the unanticipated component of policy," or "the policy surprise" in previous studies such as Kuttner (2001), Gürkaynak, Sack, and Swanson (2005a) and Bernanke and Kuttner (2005). Later in this paper policy surprises for different horizons and different types of surprises are discussed. To avoid confusion, in this paper $e_{t}^{0}$ is referred to as the "current policy surprise" or "the surprise associated with the current policy setting."

It is important to note that the assumption made about $\mu$ in the calculation of $e_{t}^{0}$ does not rule out time-varying term premia. Low frequency variation in the futures term premium (for example due to cyclical factors, as argued in Piazzesi and Swanson, 2004) would not affect the calculation of the policy surprise. It is the high frequency variation (variation around the policy date) in the term premium that should be small. Specifically, the term premium should

\footnotetext{
${ }^{8}$ For policy dates on the first day of the month, the relevant futures rate at time $t-1$ (assuming daily data) is $f^{1}$ and the policy surprise is calculated as $e_{t}^{0}=f_{t}^{0}-f_{t-1}^{1}$.
} 
not respond to the policy action.

The scaling factor adds a complication to this assumption. For a policy action on the last day of a month, for example, the change in the term premium is multiplied by 30 , amplifying the noise in the measurement of the $e_{t}^{0}$ surprise greatly. To get around this problem Kuttner (2001) suggests using the next month's contract when a policy action takes place in the last three days of the

month. In this case $e_{t}^{0}=f_{t}^{1}-f^{1}$. There is no scaling involved because the policy action affects the expected rates in the entire subsequent month (When the FOMC meetings are late in the month, there are no scheduled meetings in the subsequent month). In the applied part of this paper (section 4), the following month's contract is used whenever the scale factor is greater than four, approximately corresponding to the last week of the month.

\subsection{Changes in expected rates at longer horizons}

The policy surprise measure given by equation (4) adequately captures the surprise associated with the current target funds rate decision. If all policy surprises in policy actions change expected rates in the short-run in the same way, this is all that one would need. However, it is conceivable that different policy actions, even if they lead to the same current policy setting surprise, have different implications about the near-term path of monetary policy. Addressing such issues require measuring changes in policy expectations at slightly longer horizons.

One way of doing this is to use changes in, say, $f^{3}$. This would pick up how much interest rate expectations three months away have changed, but, in some observations there will be one scheduled FOMC meeting in three months time, in some others there will be two. The scope for rate changes is more when there are two meetings, compared to when there is only one. Thus, this measure will 
not consistently capture changes in expectations at the same FOMC meeting horizon. A better way, given the FOMC meeting frequency of interest rate target decisions, is to calculate how much the expected interest rate after the next (or a further away) FOMC has changed.

This calculation requires knowledge of the dates of future FOMC meetings, which are available extending out to at least three meetings at any point in time. The day before the current meeting, the federal funds futures contract encompassing the next meeting has the implied rate

$$
f_{t-1}^{i(1)}=\frac{d_{1}}{m_{1}} E_{t-1}\left(r_{0}\right)+\frac{m_{1}-d_{1}}{m_{1}} E_{t-1}\left(r_{1}\right)+\mu_{t-1}^{1} .
$$

The implied rate is a weighted average of the expected target rate after this meeting (which is expected to prevail until the next meeting) and the target rate expected to be the outcome of next FOMC meeting. Leading this equation one period and differencing, the change in the expected target rate after the next FOMC meeting due to the current policy announcement, $e_{t}^{1} \equiv E_{t}\left(r_{1}\right)-E_{t-1}\left(r_{1}\right)$, is

$$
e_{t}^{1}=\left[\left(f_{t}^{i(1)}-f_{t-1}^{i(1)}\right)-\frac{d_{1}}{m_{1}} e_{t}^{0}\right] \frac{m_{1}}{m_{1}-d_{1}},
$$

which once again assumes that $\mu_{t}^{1}-\mu_{t-1}^{1}$ is negligible.

Changes in interest rates expected to prevail after future FOMC meetings can be calculated as long as the date of the future FOMC is known and there is trading in the federal funds futures contract covering the month of that meeting. The change in the expected interest rate after the $n^{\text {th }}$ FOMC meeting due to the current policy announcement is

$$
e_{t}^{n}=\left[\left(f_{t}^{i(n)}-f_{t-1}^{i(n)}\right)-\frac{d_{n}}{m_{n}} e_{t}^{n-1}\right] \frac{m_{n}}{m_{n}-d_{n}} .
$$

Note that the scale factor depends on when in the month the $n^{\text {th }}$ meeting is, 
not on when the current meeting is. If the scale factor is large (for meetings that will take place towards the end of a month), the change in expected future interest rates can be calculated as $e_{t}^{n}=f_{t}^{i(n)+1}-f_{t-1}^{i(n)+1}$.

\subsection{Interest rate level and policy expectations}

Although the usual object of interest in policy analysis is the policy surprise as measured by changes in expected rates, federal funds futures can also be used to calculate expected interest rates and expected policy moves. Of course, calculating the expected rates after several FOMC meetings is the essence of calculating the surprise at these horizons. The surprise, after all, is the change in the expected rates on the policy date.

The expected interest rate on the day of current meeting, $t$, using equation $(5)$, is $^{9}$

$$
E_{t}\left(r_{1}\right)=\left[f_{t}^{i(1)}-\frac{d_{1}}{m_{1}} r_{0}-\mu_{t}^{i(1)}\right] \frac{m_{1}}{m_{1}-d_{1}}
$$

Importantly, in calculating expected levels of interest rates, the term premium does not drop out because there is no differencing involved. Gürkaynak, Sack, and Swanson (2002) estimate the term premium in federal funds futures contracts to be very small, about one to three basis points per month, which can be used to substitute for $\mu^{i(j)} \cdot{ }^{10}$

Expected interest rates at longer horizons can similarly be calculated recursively, with the expected interest rate after the $j^{\text {th }}$ FOMC given by

$$
E_{t}\left(r_{j}\right)=\left[f_{t}^{i(j)}-\frac{d_{j}}{m_{j}} E_{t}\left(r_{j-1}\right)-\mu_{t}^{i(j)}\right] \frac{m_{j}}{m_{j}-d_{j}} .
$$

\footnotetext{
${ }^{9}$ If this calculation is done at time $t-1$, before the outcome of the current FOMC meeting is known, $E_{t-1}\left(r_{0}\right)$ has to be estimated first using the known $r_{-1}$, as described in equation (8). Here, it would matter if observed effective funds rates are different from target rates. If the difference is noticeable (which happens rarely) the observed average effective rate in the current month until today can be substituted for $r_{-1}$.

${ }^{10}$ Also see Durham (2003) and Sack (2004) about the term-premium in federal funds futures.
} 
Calculating the expected rates at different FOMC horizons and plotting these makes a beautiful step-path. Figure 1 shows the step-path on August 12 and August 13, 2002, an FOMC meeting day. This was a time when the FOMC was aggressively cutting rates, thus expected rates were lower at longer horizons. The changes in expected rates in the day of the meeting are the policy surprise measures (the $e^{j}$ 's) calculated above. On August 13, 2002, the current policy surprise was positive although the target rate was not changed. Investors had attributed positive probability to a 25 basis point easing that did not materialize. On the other hand, expected rates after more distant FOMC meetings moved in the opposite direction and fell some. Thus, on this date the positive current policy surprise was not indicative of how short-run interest rate expectations changed. This differential response of expectations at different horizons to monetary policy surprises will be analyzed in detail in section 4 below.

Equipped with equation (8), it is easy to calculate expectations about future policy actions, $E_{t}\left(r_{j}-r_{j-1}\right)$, by simply differencing equation (8) for two consecutive expected rates, which yields the difference equation ${ }^{11}$

$$
E_{t}\left(r_{j}-r_{j-1}\right)=\left[f_{t}^{i(j)}-E_{t}\left(r_{j-1}\right)-\mu_{t}^{i(j)}\right] \frac{m_{j}}{m_{j}-d_{j}} .
$$

The expected policy actions are the heights of the steps in figure 4. In particular, the next expected policy action is

$$
E_{t}\left(r_{1}\right)-r_{0}=\left[f_{t}^{i(1)}-r_{0}-\mu_{t}^{i(1)}\right] \frac{m_{j}}{m_{j}-d_{j}} .
$$

Thus, we can calculate not only what the expected funds rate is at some future date, but also the expected pace of getting there.

\footnotetext{
${ }^{11}$ Note that this is a difference equation in $j$, not in time.
} 
Given the expected rates at FOMC horizons as a time series, other policy expectations related quantities can also be calculated. For example, it is trivial to calculate how much the expectations about the next policy action has changed on the day of the current FOMC meeting, by differencing equation (9) over time.

This section demonstrated that the usefulness of federal funds futures extend beyond calculating the surprise associated with the current setting of monetary policy and showed ways of extracting more information from these contracts. The next section provides an empirical application using policy surprises at longer horizons.

\section{Decomposing policy surprises}

\subsection{Timing and level}

The recent eventstudy literature on measuring the effects of monetary policy on asset prices (Kuttner, 2001, Bernanke and Kuttner, 2005, Gürkaynak, Sack and Swanson, 2005b) uses regressions of the form

$$
\Delta y_{t}=\alpha+\beta \text { surprise }_{t}+\varepsilon_{t},
$$

where $\Delta y_{t}$ is the change in the asset price or return around the policy announcement and $\varepsilon_{t}$ captures the changes in $y_{t}$ that are not due to monetary policy. Although the standard in this literature is to use daily observations, Gürkaynak, Sack and Swanson (2005b) construct an intraday data set and show that there are considerable gains in precision from using intraday data. The empirical exercises in this paper employ this data set, measuring changes in asset prices (including federal funds futures) in a thirty-minute window around the policy announcement, starting from ten minutes before the event, and ending twenty minutes after. Note that the policy announcement was an implicit an- 
nouncement before 1994, when markets had to infer the change in the policy stance from the following day's open market operation. The measurement window is around the point in time when policy news reach financial markets (the announcement time), rather than when the policy decision is actually made.

$e^{0}, e^{1}$, and $e^{2}$ are most often calculated from the first, third, and fifth federal funds futures contracts. The first and third contracts' liquidity is low in the early 1990s, but it increases substantially starting from 1994, while the fifth contract is very illiquid before 1998. In the empirical part of this paper, analysis is carried out for the full sample when only $e^{0}$ and $e^{1}$ are used and results for the post-1994 sample are presented as a robustness check. The sample is limited to post-1998 when $e^{2}$ is also employed.

In regressions of the form (11), using $e^{0}$ as the policy surprise measure is common as this captures the surprise associated with the current setting of policy, the usual definition of policy surprise. However, some authors prefer changes in longer dated securities, such as three month eurodollar futures (Rigobon and Sack, 2002), or the change in the third federal funds futures rate, $f^{3}$, (Bernanke and Kuttner, 2005) instead of $e^{0}$ or as a robustness check. The reason for using changes in expected rates at longer maturities is to capture relatively more permanent changes in expected interest rates, rather than surprises that have a small impact on expected rates in the near future.

Consider a stylized example where, say, at the end of a tightening cycle financial markets expect one last 25 basis point target rate increase. Assume that investors attach equal probability to the tightening taking place in this meeting or the next one (but certainly one or the other), and then expect no further changes. If the last tightening takes place in this meeting, it will be a positive tightening surprise (12.5 basis points) as measured by $e^{0}$, but expected rates after the next FOMC will not change, that is, $e^{1}$ will be zero. ${ }^{12}$ The

\footnotetext{
${ }^{12}$ If the policy move does not happen in the current meeting, it will be measured as a 12.5
} 
implications of this surprise for asset prices is likely to be very different from a 12.5 basis point current policy setting surprise that leads investors to revise up their expectations of the funds rate in the near future in a parallel fashion.

This transitory versus permanent surprise idea can be formalized better by defining a pure timing surprise. An obvious (but certainly not the only possible) definition of a timing surprise is a policy surprise that leaves expected interest rates after the next FOMC unchanged. With this timing construct, the change in expected rates after the next meeting, $e_{t}^{1}$, would not have a transitory component by definition. In this case, $e_{t}^{1}$ can be thought of as providing a measure of the parallel shift of interest rate expectations, i.e. as defining a level surprise. ${ }^{13}$ That is

$$
\begin{aligned}
e_{t}^{0} & =\alpha_{1} \text { level }_{t}+\text { timing }_{t}, \\
e_{t}^{1} & =\text { level }_{t} .
\end{aligned}
$$

A regression of $e_{t}^{0}$ on $e_{t}^{1}$ will decompose the surprise in the current policy announcement into level and timing components, where timing will be the residual. ${ }^{14}$ This way of 'defining' different types of monetary policy surprises is similar in spirit to VAR identification. Timing is essentially constructed by a zero restriction. Similar to identified VARs, one can think of alternative identifying assumptions. For example, level can be defined as, say, $e^{3}$, and timing as the component of $e^{0}$ that is orthogonal to $e^{3}$. The timing and level constructs used in this paper are the probably the most intuitive ones and in section 4.1.1 it will be shown that the two components behave in a way that is consistent

basis point surprise easing in terms of $e^{0}$, but $e^{1}$ will again be zero.

${ }^{13}$ Gürkaynak, Sack, and Swanson (2002) also propose a similar timing/level decomposition, but that paper does not investigate asset price implications of the two types of surprises.

${ }^{14}$ Although equations (12) and (13) are exact, in reality the prices of federal funds futures contracts and the surprise measures constructed from them are likely to include some idiosyncratic noise. This will cause the coefficient estimates in regressions using these measures on the right hand side to be biased down some. The same potential errors in variables problem also applies to analyses using $e^{0}$ or other market-based surprises on the right hand side. 
with their names. Note that the level and timing components constructed this way, like fundamental VAR shocks, will be orthogonal to each other.

Table $1 \mathrm{~A}$ reports the results of the regression that decomposes $e^{0}$ into level and timing. The $R^{2}$ (at $47 \%$ ) suggests that timing surprises constitute a large part of the current policy surprise. The coefficient on level is not significantly different from unity, which is consistent with defining level as a parallel shift of short-term expected interest rates.

\subsubsection{Asset price responses to timing and level surprises}

The asset price response to timing and level surprises can be studied by extending regression equation (11), to include two surprise variables:

$$
\Delta y_{t}=\alpha+\beta_{1} \text { timing }_{t}+\beta_{2} \text { level }_{t}+\varepsilon_{t} .
$$

Regressions of the from (14) pose a difficulty in calculating the standard errors because timing is a constructed variable. To calculate reliable standard errors that take account of the variation stemming from the first step regression (estimation of timing) the regression coefficients are bootstrapped. In each bootstrap replication $e^{0}, e^{1}$, and the left-hand side variable are sampled together and timing is estimated for that sample, which is then used in estimating equation (14). This procedure is repeated 1000 times and standard errors of coefficients in (14) are calculated as the standard deviation of the distribution resulting from the bootstrapping exercise. ${ }^{15}$ Bootstrapped standard errors are larger than OLS standard errors, as expected.

The results of the regressions are presented in table $1 \mathrm{~B}$, where results using the standard monetary policy surprise, $e^{0}$, are also presented for reference in the

\footnotetext{
${ }^{15}$ Significance tests are based on normal approximation, which agree with the percentile method in almost all cases.
} 
first column. ${ }^{16}$ This current policy setting surprise has a large and statistically significant effect on Treasury yields, with the effect becoming smaller as the horizon increases. The timing surprise also has a large and statistically significant impact on shorter-term yields. Although short lived, the timing surprise does have a mechanical effect on yields that is important at short horizons. Assuming that the average duration of a timing surprise is 1.5 months (12 months divided by 8 scheduled FOMC meetings a year) a one percentage point timing surprise should move the three-month yield by 50 basis points, which is about the estimated effect. The effect of the timing surprise declines as the maturity increases (the effect is not significantly different from zero at five and ten year horizons), and its explanatory power declines even faster (the $R^{2}$ falls to seven percent for the two-year yield). ${ }^{17}$

The level component of monetary policy surprise and $e^{0}$ have about the same effect on the three month yield. Differentiating between level and timing does not matter much at this maturity because timing itself has a sizable impact. However, as maturity lenghtens the choice of the policy surprise measure becomes important. Since the current policy setting surprise is a combination of the timing and level surprises, and the timing surprise has no effect on longer term yields, the $e^{0}$ measure understates the effects of a shift in the monetary policy stance on these yields. The point estimates when the policy surprise is measured by level surprise are up to fifteen basis points higher than those using the current policy surprise. Using the level surprise also improves the explanatory power of the regressions, as can be seen from the increased $R^{2}$ statistics.

\footnotetext{
${ }^{16}$ The sample starts in July 1991 because the intraday data on on-the-run Treasury securities that are on the left-hand side of these regressions are available only since this date. Two outliers, the policy actions on January 3, 2001 and September 17, 2001 are excluded, the former because of the outsized stock price movement that day, the latter because of the volatility in financial markets unrelated to monetary policy.

${ }^{17}$ The large and significant effect of the timing surprise on the two year yield is surprising, even though the $R^{2}$ is very low. This seems to be due to a few high-leverage observations, and it is not present in the post-1998 sample, discussed below.
} 
The bottom row of table $1 \mathrm{~B}$ reports the effects of $e^{0}$, timing, and level surprises on stock prices, measured by the percentage change in S\&P 500. The effect using $e^{0}$ is estimated to be -2.93 percent, while it is -3.85 percent using the level surprise. Employing the current rate surprise as the policy surprise measure understates the effect of monetary policy on stock prices by a percentage point as the timing component has a small and insignificant effect. ${ }^{18}$

Tables $2 \mathrm{~A}$ and $2 \mathrm{~B}$ repeat the same exercise for a shorter sample starting at 1994. The results are robust to this change of sample; most of the estimated parameters are about the same as those for the full sample. A notable exception is the stock price regression where the coefficients of both the current rate surprise and the level surprise are larger (in absolute value). In general, it seems that the relatively lower pre-1994 liquidity of the federal funds futures contracts used in the construction of the $e^{0}$, timing, and level surprises has not influenced the full sample results.

Overall, it turns out that timing has a significant effect only on short-term yields and for that reason differentiating between timing surprises and level surprises does make a difference. The "policy surprise" concept does not usually refer to timing surprises, but its usual empirical counterpart, $e^{0}$, often includes timing as well as level surprises and therefore understates the effects of monetary policy on asset prices.

\subsection{Timing, level, and slope}

The decomposition presented above assumed that policy surprises consist of only timing and level components. This assumption is overly restrictive, as the FOMC is able to shape future policy expectations with the statements it releases after its meetings (Gürkaynak, Sack, and Swanson 2005b, Ellingsen and

\footnotetext{
${ }^{18}$ The parameter estimates presented here are not directly comparable to Bernanke and Kuttner (2005) due to different sample periods, but are in line with their results.
} 
Söderström 2001, 2003). These statements often lead to revisions to expected pace of interest rate changes, that is, it is likely that policy surprises have a slope component as well as level and timing components.

This paper identifies slope in a manner similar to its treatment of timing-as a residual. If $e^{0}$ consists of level and timing and $e^{1}$ is only level (an assumption that worked well above), a longer-dated change in expected interest rates is needed to identify slope. For this purpose $e^{2}$ is used. Specifically, timing, level, and slope are identified using changes in expected rates at three horizons, assuming that

$$
\begin{aligned}
e_{t}^{0} & =\alpha_{1} \text { level }_{t}+\text { timing }_{t}, \\
e_{t}^{1} & =\text { level }_{t}, \\
e_{t}^{2} & =\alpha_{2} \text { level }_{t}+\text { slope }_{t} .
\end{aligned}
$$

It should be emphasized again that this decomposition, like the timing vs. level decomposition carried out in section 4.1, is one of many ways one could think about timing, level, and slope. These components are empirical constructs, and given this specific way of constructing them, they may not behave in a way consistent with their names but it turns out that they do. We had seen above that timing and level do indeed behave like a transitory and a more permanent surprise. Now we turn to the econometric analysis in the post-1998 sample, adding slope as a third policy surprise component.

Table $3 \mathrm{~A}$ shows the results of the two regressions used in the construction of timing and slope surprises, again using $e^{1}$ as level. The first regression shows that the coefficient of level in $e^{0}$ is still not statistically different from unity, and also that the contribution of timing (the residual) to the current policy surprise is somewhat smaller in this more recent sample $-R^{2}$ is 68 percent rather than the 47 percent before. 
The second regression is for constructing slope. Slope is estimated as the residual of regressing $e^{2}$ on level and timing. Although it is not present in equation (15), timing is included in this regression to ensure that the three components of policy surprises are orthogonal to each other. Consistent with the definition of timing as the component of the policy surprise that does not change expected interest rates after the next FOMC meeting, the coefficient of timing on $e^{2}$ (change in expected rates after the second FOMC meeting) is not significantly different from zero. Like timing, level also behaves as its name suggests, with a coefficient not significantly different from unity. ${ }^{19}$ About 20 percent of the variation in $e^{2}$ is due to slope. The four panels of Figure 2 show the current policy surprise and the timing, level, and slope surprises in the post-1998 sample.

\subsubsection{Asset price responses to timing, level, and slope surprises}

The effects of the three factors on asset prices are presented in Table 3A, using regressions of the form

$$
\Delta y_{t}=\alpha+\beta_{1} \text { timing }_{t}+\beta_{2} \text { level }+\beta_{3} \text { slope }+\varepsilon_{t},
$$

where the standard errors are once again bootstrapped. For each bootstrap sample first timing, then slope is estimated and then these are used in estimating (16). Standard errors are calculated from the distributions of 1000 bootstrap estimates.

The effects of the current policy surprise $\left(e^{0}\right)$, timing, and level are similar to those reported in Table 1B for the full 1991-2004 sample. The notable differences are the much smaller and insignificant coefficient of timing on the two-year yield, the insignificance of $e^{0}$ and level on the ten-year yield, and the larger impact of $e^{0}$

\footnotetext{
${ }^{19}$ Note that the standard errors in the second regression are bootstrapped using the method described in section 4.1.1.
} 
and level on the stock prices. Finding that timing does not significantly affect the two-year yield is expected as its earlier large and significant coefficient was due to a handful of high leverage observations that drop out in this sample. Gürkaynak, Sack, and Swanson (2005a) show that the effect of $e^{0}$ on long forward rates is negative, which would offset the positive effect of these surprises on short term yields when the ten-year yield is the object of analysis. This effect seems to be stronger in the more recent sample, leading to the insignificant coefficient.

The effects of the slope surprise are shown in the right-most panel of table 3B. Slope has a relatively small effect on the three-month yield. On most policy dates, the slope component of monetary policy surprise refers to changes in expectations further away than three months, thus this small coefficient is to be expected. Its effect is much larger than the effects of level for the two- five-, and ten-year yields, significant at all maturities. The slope surprise appears to help shape expectations of interest rates extending to long horizons. On the other hand, the effect of the slope surprise on $\mathrm{S} \& \mathrm{P} 500$ is insignificantly different from zero (although the point estimate is not small). This may suggest that slope reflects the markets' reading of the economic outlook from the policy announcement, together with the implied policy path. If the central bank is signaling higher rates in the near future due to inflationary worries, stock prices will fall, if the outlook is for a rapidly growing economy, stock prices will be supported by this. To the extent that the slope surprise is a mixture of these two, its effect on stock prices will be ambiguous. Fixed-income yields, of course, will go up in either case.

In this paper, slope is calculated using changes in expected rates out to about five months. This assumes that changes in expected rates within this horizon reflect investors' direct inference about the interest rates from the policy announcement (the exogenous policy surprise given their information about 
the central bank's preferences and the state of the economy), while changes in

longer-term rates are responses to these policy surprises. The distinction between what is a policy surprise and what constitutes a response to this surprise is, admittedly, somewhat arbitrary.

In an other paper that pursues a similar idea, Gürkaynak, Sack, and Swanson (2005b) assume that all changes in expected rates within a one-year horizon are reflections of the forward looking signal associated with the policy announcement, while changes in expected rates with longer maturities are responses to these. They use this assumption to do a factor decomposition and create a target and a path factor surprise, without dwelling on the timing component. Their target factor is similar to $e^{0}$, while the path factor behaves like the slope component calculated from changes in expected rates about a year ahead. That paper makes a stronger assumption about the information content of the policy announcement by assuming that the direct policy signal that can be extracted from the policy action and the statement extends out to a year. Clearly, there is room for more research to understand the horizon of the monetary policy signal, in which dimensions monetary policy surprises differ, and what effects these different surprises have on financial markets.

\section{Conclusions}

Market-based measures of monetary policy expectations and surprises are useful because these can be calculated at high frequencies and are free of the often implausible assumptions of VAR based exercises when responses of asset prices are concerned. A favorite instrument for these measures is the federal funds futures contract. This paper demonstrated the usefulness of these contracts beyond their use in calculating the unanticipated component of the current target rate decision. The federal funds futures market is liquid out to at 
least six months, and given the knowledge of the dates of future FOMC meetings, expectations and changes in expectations due to policy announcements can be calculated at different FOMC meeting horizons, which are the relevant intervals for interest rate changes.

The first part of this paper showed the mechanics of extracting information from the prices of federal funds futures contracts. The second part used these market-based changes in expected funds rates after several FOMC meetings to help think about monetary policy as a multi-dimensional process. Rather than estimating the asset price responses to the "average" policy surprise, unanticipated policy actions are decomposed into timing, level, and slope surprises. The estimated asset price reactions to these surprise components differ significantly. While timing surprises have little effect beyond short-maturity yields, the responses to the level component suggest that the effect of a lasting policy surprise (one that actually changes expectations of funds rates for longer than an intermeeting period) are large-and these effects are understated when the "unexpected current policy action" measure of policy surprises is used. Lastly, the slope surprise has a large influence on longer term yields, perhaps because these are perceived to be informative about the central bank's economic outlook.

The timing, level, and slope decomposition carried out in this paper was a purely empirical exercise. An interesting avenue for research would be to model the monetary policy process as consisting of more than one type of surprise, and to investigate the theoretical implications. This would tie into the role of commitment in monetary policy and differences between committing to an interest rate path rather than to an outcome, such as a level of inflation. Of course, there is significant scope for more empirical work as well. The applied exercise in this paper used only part of what can be learned from federal funds futures contracts. Further research utilizing information embedded in these 
instruments will help in better understanding how monetary policy and financial markets interact. 


\section{References}

[1] Bernanke, Ben and Kenneth Kuttner (2005). "What Explains the Stock Market's Reaction to Federal Reserve Policy?" Journal of Finance, forthcoming.

[2] Cook, Timothy and Thomas Hahn (1989). "The Effect of Changes in the Federal Funds Rate Target on Market Interest Rates in 1970s," Journal of Monetary Economics 24, 331-51.

[3] Craine, Roger and Vance Martin (2004). "Monetary Policy Shocks and Security Market Responses," working paper, University of California at Berkeley.

[4] Durham, Benson (2003), "Estimates of the Term Premium on Near-dated Federal Funds Futures Contracts," Federal Reserve Board Finance and Economics Discussion Series 2003-19.

[5] Ellingsen, Tore and Ulf Söderström (2001). "Monetary Policy and Market Interest Rates," American Economic Review 91, 1594-1607.

[6] Ellingsen, Tore and Ulf Söderström (2003). "Monetary Policy and the Bond Market," working paper, Bocconi University.

[7] Gürkaynak, Refet, Brian Sack, and Eric Swanson (2002). "Market-Based Measures of Monetary Policy Expectations," Federal Reserve Board Finance and Economics Discussion Series 2002-40.

[8] Gürkaynak, Refet, Brian Sack, and Eric Swanson (2005a). "The Sensitivity of Long-Term Interest Rates to Economic News: Evidence and Implications for Macroeconomic Models," American Economic Review 95, 425-36.

[9] Gürkaynak, Refet, Brian Sack, and Eric Swanson (2005b). "Do Actions Speak Louder Than Words? The Response of Asset Prices to Monetary Policy Actions and Statements," International Journal of Central Banking 1, 55-93.

[10] Hamilton, James and Oscar Jorda (2002). "A Model of the Federal Funds Rate Target," Journal of Political Economy 110, 1135-67.

[11] Krueger, Joel and Kenneth Kuttner (1996). "The Fed Funds Futures Rate as a Predictor of Federal Reserve Policy," Journal of Futures Markets 16, 865-879.

[12] Kuttner, Kenneth (2001). "Monetary Policy Surprises and Interest Rates: Evidence from the Fed Funds Futures," Journal of Monetary Economics $47,523-44$.

[13] Piazzesi, Monika and Eric Swanson (2004). "Futures Rates as RiskAdjusted Forecasts of Monetary Policy," NBER Working Paper No. 10547. 
[14] Rigobon, Roberto and Brian Sack (2002). "The Impact of Monetary Policy on Asset Prices," NBER Working Paper No. 8794.

[15] Rudebusch, Glenn (1998). "Do Measures of Monetary Policy in a VAR Make Sense?" International Economic Review 39, 907-931.

[16] Sack, Brian (2004). "Extracting the Expected Path of Monetary Policy From Futures Rates," Journal of Futures Markets 24, 733-54.

[17] Söderström, Ulf (2001). "Predicting Monetary Policy with Federal Funds Futures Prices," Journal of Futures Markets 21, 377-91. 
Table 1.A: Generating the timing component

\begin{tabular}{|c|c|c|c|c|}
\hline $\begin{array}{r}\text { Dependent } \\
\text { Variable }\end{array}$ & $\begin{array}{l}\text { Constant } \\
\text { (std err) }\end{array}$ & $\begin{array}{c}\text { Level } \\
\text { (std err) }\end{array}$ & $\mathrm{R}^{2}$ & \\
\hline$e^{0}$ & $\begin{array}{c}-0.001 \\
(0.005)\end{array}$ & $\begin{array}{c}\mathbf{0 . 8 5 9} \\
(0.121)\end{array}$ & 0.49 & \\
\hline
\end{tabular}

Note. Number of observations is 119. Heteroskedasticity consistent standard errors are reported in parentheses. Coefficients in bold are significant at $5 \%$.

Table 1.B: Response of asset prices to timing and level factors

\begin{tabular}{|c|c|c|c|c|c|c|c|c|c|c|}
\hline $\begin{array}{r}\text { Dependent } \\
\text { Variable } \\
\end{array}$ & $\begin{array}{l}\text { Constant } \\
\text { (std err) }\end{array}$ & $\begin{array}{c}e^{0} \\
\text { (std err) }\end{array}$ & $\mathrm{R}^{2}$ & $\begin{array}{r}\text { Constant } \\
\text { (std err) }\end{array}$ & $\begin{array}{c}\text { Timing } \\
\text { (std err) }\end{array}$ & $\mathrm{R}^{2}$ & $\begin{array}{l}\text { Constant } \\
\text { (std err) }\end{array}$ & $\begin{array}{r}\text { Timing } \\
\text { (std err) }\end{array}$ & $\begin{array}{c}\text { Level } \\
\text { (std err) }\end{array}$ & $\mathrm{R}^{2}$ \\
\hline 3-month & $\begin{array}{c}\mathbf{- 0 . 0 0 6} \\
(0.002)\end{array}$ & $\begin{array}{c}\mathbf{0 . 5 6 4} \\
(0.040)\end{array}$ & 0.80 & $\begin{array}{c}\mathbf{- 0 . 0 1 4} \\
(0.005)\end{array}$ & $\begin{array}{c}\mathbf{0 . 4 7 9} \\
(0.061)\end{array}$ & 0.29 & $\begin{array}{c}-0.005 \\
(0.003)\end{array}$ & $\begin{array}{c}\mathbf{0 . 4 7 9} \\
(0.064)\end{array}$ & $\begin{array}{c}\mathbf{0 . 5 6 2} \\
(0.068)\end{array}$ & 0.82 \\
\hline 6-month & $\begin{array}{c}-0.005 \\
(0.003)\end{array}$ & $\begin{array}{c}\mathbf{0 . 5 6 3} \\
(0.050)\end{array}$ & 0.64 & $\begin{array}{c}\mathbf{- 0 . 0 1 3} \\
(0.006)\end{array}$ & $\begin{array}{c}\mathbf{0 . 3 9 3} \\
(0.064)\end{array}$ & 0.16 & $\begin{array}{c}-0.003 \\
(0.003)\end{array}$ & $\begin{array}{c}\mathbf{0 . 3 9 3} \\
(0.060)\end{array}$ & $\begin{array}{c}\mathbf{0 . 6 3 7} \\
(0.089)\end{array}$ & 0.70 \\
\hline 2-year & $\begin{array}{c}-0.002 \\
(0.004)\end{array}$ & $\begin{array}{c}\mathbf{0 . 5 2 8} \\
(0.064)\end{array}$ & 0.46 & $\begin{array}{c}-0.010 \\
(0.006)\end{array}$ & $\begin{array}{c}\mathbf{0 . 2 8 4} \\
(0.089)\end{array}$ & 0.07 & $\begin{array}{c}0.001 \\
(0.004)\end{array}$ & $\begin{array}{c}\mathbf{0 . 2 8 4} \\
(0.094)\end{array}$ & $\begin{array}{c}\mathbf{0 . 6 7 6} \\
(0.088)\end{array}$ & 0.56 \\
\hline 5-year & $\begin{array}{c}0.000 \\
(0.004)\end{array}$ & $\begin{array}{c}\mathbf{0 . 3 3 3} \\
(0.059)\end{array}$ & 0.26 & $\begin{array}{c}-0.005 \\
(0.005)\end{array}$ & $\begin{array}{c}0.151 \\
(0.790)\end{array}$ & 0.03 & $\begin{array}{c}0.002 \\
(0.004)\end{array}$ & $\begin{array}{c}0.151 \\
(0.080)\end{array}$ & $\begin{array}{c}\mathbf{0 . 4 5 2} \\
(0.091)\end{array}$ & 0.35 \\
\hline 10-year & $\begin{array}{c}-0.001 \\
(0.003)\end{array}$ & $\begin{array}{c}\mathbf{0 . 1 7 0} \\
(0.051)\end{array}$ & 0.13 & $\begin{array}{c}-0.004 \\
(0.004)\end{array}$ & $\begin{array}{c}0.050 \\
(0.067)\end{array}$ & 0.01 & $\begin{array}{c}0.000 \\
(0.003)\end{array}$ & $\begin{array}{c}0.050 \\
(0.067)\end{array}$ & $\begin{array}{c}\mathbf{0 . 2 5 6} \\
(0.081)\end{array}$ & 0.20 \\
\hline S\&P 500 & $\begin{array}{c}\mathbf{- 0 . 0 9 9} \\
(0.037)\end{array}$ & $\begin{array}{c}-2.930 \\
(0.889)\end{array}$ & 0.24 & $\begin{array}{c}-0.057 \\
(0.049)\end{array}$ & $\begin{array}{r}-1.500 \\
(0.964)\end{array}$ & 0.03 & $\begin{array}{c}\mathbf{- 0 . 1 1 8} \\
(0.037)\end{array}$ & $\begin{array}{c}-1.500 \\
(0.970)\end{array}$ & $\begin{array}{c}-3.813 \\
(1.018)\end{array}$ & 0.30 \\
\hline
\end{tabular}

Note. Number of observations is 119. Heteroskedasticity consistent standard errors are reported for $e^{0}$ regressions. Bootstrap standard errors, as explained in text, are reported for regressions using timing. $\mathrm{R}^{2}$ statistics refer to OLS goodness-of-fit measures. Coefficients in bold are significant at 5\%. 
Table 2.A: Generating the timing component (post-1994)

\begin{tabular}{|c|c|c|c|c|}
\hline $\begin{array}{r}\text { Dependent } \\
\text { Variable }\end{array}$ & $\begin{array}{l}\text { Constant } \\
\text { (std err) }\end{array}$ & $\begin{array}{c}\text { Level } \\
\text { (std err) }\end{array}$ & $\mathrm{R}^{2}$ & \\
\hline$e^{0}$ & $\begin{array}{c}0.001 \\
(0.006)\end{array}$ & $\begin{array}{c}\mathbf{0 . 8 1 4} \\
(0.136)\end{array}$ & 0.47 & \\
\hline
\end{tabular}

Note. Number of observations is 91. Heteroskedasticity consistent standard errors are reported in parentheses. Coefficients in bold are significant at $5 \%$.

Table 2.B: Response of asset prices to timing and level factors (post-1994)

\begin{tabular}{|c|c|c|c|c|c|c|c|c|c|c|}
\hline $\begin{array}{r}\text { Dependent } \\
\text { Variable }\end{array}$ & $\begin{array}{l}\text { Constant } \\
\text { (std err) }\end{array}$ & $\begin{array}{c}e^{0} \\
\text { (std err) }\end{array}$ & $\mathrm{R}^{2}$ & $\begin{array}{l}\text { Constant } \\
\text { (std err) }\end{array}$ & $\begin{array}{l}\text { Timing } \\
\text { (std err) }\end{array}$ & $\mathrm{R}^{2}$ & $\begin{array}{l}\text { Constant } \\
\text { (std err) }\end{array}$ & $\begin{array}{l}\text { Timing } \\
\text { (std err) }\end{array}$ & $\begin{array}{c}\text { Level } \\
\text { (std err) }\end{array}$ & $\mathrm{R}^{2}$ \\
\hline 3-month & $\begin{array}{c}\mathbf{- 0 . 0 0 6} \\
(0.003)\end{array}$ & $\begin{array}{c}\mathbf{0 . 5 9 4} \\
(0.050)\end{array}$ & 0.80 & $\begin{array}{c}\mathbf{- 0 . 0 1 2} \\
(0.006)\end{array}$ & $\begin{array}{c}\mathbf{0 . 5 2 3} \\
(0.076)\end{array}$ & 0.33 & $\begin{array}{c}-0.004 \\
(0.004)\end{array}$ & $\begin{array}{c}\mathbf{0 . 5 2 3} \\
(0.077)\end{array}$ & $\begin{array}{c}\mathbf{0 . 5 4 9} \\
(0.094)\end{array}$ & 0.81 \\
\hline 6-month & $\begin{array}{c}-0.006 \\
(0.004)\end{array}$ & $\begin{array}{c}\mathbf{0 . 5 7 8} \\
(0.065)\end{array}$ & 0.64 & $\begin{array}{c}\mathbf{- 0 . 0 1 2} \\
(0.006)\end{array}$ & $\begin{array}{c}\mathbf{0 . 3 9 6} \\
(0.086)\end{array}$ & 0.16 & $\begin{array}{c}-0.003 \\
(0.004)\end{array}$ & $\begin{array}{c}\mathbf{0 . 3 9 6} \\
(0.085)\end{array}$ & $\begin{array}{c}\mathbf{0 . 6 4 0} \\
(0.113)\end{array}$ & 0.72 \\
\hline 2-year & $\begin{array}{c}-0.002 \\
(0.006)\end{array}$ & $\begin{array}{c}\mathbf{0 . 5 0 6} \\
(0.081)\end{array}$ & 0.37 & $\begin{array}{c}-0.007 \\
(0.007)\end{array}$ & $\begin{array}{c}\mathbf{0 . 2 4 0} \\
(0.116)\end{array}$ & 0.04 & $\begin{array}{c}0.002 \\
(0.005)\end{array}$ & $\begin{array}{c}\mathbf{0 . 2 4 0} \\
(0.118)\end{array}$ & $\begin{array}{c}\mathbf{0 . 6 6 0} \\
(0.115)\end{array}$ & 0.49 \\
\hline 5-year & $\begin{array}{c}0.000 \\
(0.006)\end{array}$ & $\begin{array}{c}\mathbf{0 . 3 0 1} \\
(0.074)\end{array}$ & 0.18 & $\begin{array}{c}-0.002 \\
(0.006)\end{array}$ & $\begin{array}{c}0.092 \\
(0.104)\end{array}$ & 0.01 & $\begin{array}{c}0.003 \\
(0.005)\end{array}$ & $\begin{array}{c}0.092 \\
(0.108)\end{array}$ & $\begin{array}{c}\mathbf{0 . 4 4 1} \\
(0.129)\end{array}$ & 0.28 \\
\hline 10-year & $\begin{array}{c}-0.001 \\
(0.004)\end{array}$ & $\begin{array}{c}\mathbf{0 . 1 5 8} \\
(0.069)\end{array}$ & 0.09 & $\begin{array}{c}-0.002 \\
(0.005)\end{array}$ & $\begin{array}{c}0.017 \\
(0.094)\end{array}$ & 0.00 & $\begin{array}{c}0.001 \\
(0.004)\end{array}$ & $\begin{array}{c}0.017 \\
(0.090)\end{array}$ & $\begin{array}{c}\mathbf{0 . 2 6 0} \\
(0.124)\end{array}$ & 0.16 \\
\hline S\&P 500 & $\begin{array}{c}\mathbf{- 0 . 1 2 7} \\
(0.048) \\
\end{array}$ & $\begin{array}{c}-3.648 \\
(0.991) \\
\end{array}$ & 0.28 & $\begin{array}{c}-0.091 \\
(0.060) \\
\end{array}$ & $\begin{array}{c}-1.873 \\
(1.145) \\
\end{array}$ & 0.04 & $\begin{array}{c}\mathbf{- 0 . 1 5 4} \\
(0.045) \\
\end{array}$ & $\begin{array}{c}-1.873 \\
(1.164) \\
\end{array}$ & $\begin{array}{c}-4.628 \\
(1.389) \\
\end{array}$ & 0.36 \\
\hline
\end{tabular}

Note. Number of observations is 91 . Heteroskedasticity consistent standard errors are reported for $e^{0}$ regressions. Bootstrap standard errors, as explained in text, are reported for regressions using timing and level. $\mathrm{R}^{2}$ statistics refer to OLS goodness-of-fit measures. Coefficients in bold are significant at $5 \%$. 
Table 3.A: Generating the timing and slope components (post-1998)

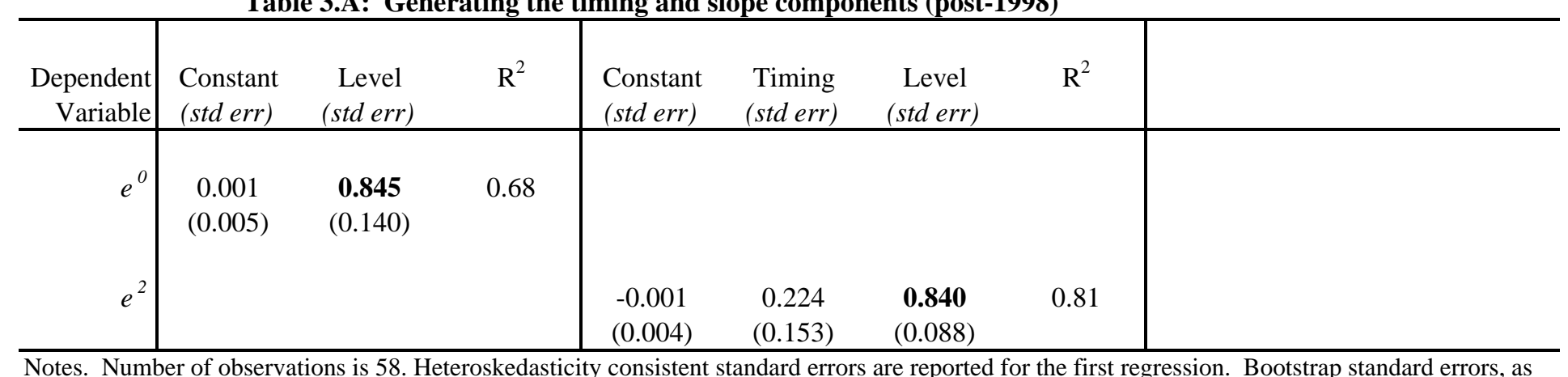

Notes. Number of observations is 58. Heteroskedasticity consistent standard errors are reported for the first regression. Bootstrap standard errors, as explained in text, are reported for the second regression. $\mathrm{R}^{2}$ statistics refer to OLS goodness-of-fit measures. Coefficients in bold are significant at $5 \%$. 
Table 3.B: Response of asset prices to timing, level, and slope factors (post-1998)

\begin{tabular}{|c|c|c|c|c|c|c|c|c|c|c|c|c|c|c|c|}
\hline $\begin{array}{r}\text { Dependent } \\
\text { Variable } \\
\end{array}$ & $\begin{array}{l}\text { Constant } \\
\text { (std err) }\end{array}$ & $\begin{array}{c}e^{0} \\
\text { (std err) }\end{array}$ & $\mathrm{R}^{2}$ & $\begin{array}{l}\text { Constant } \\
\text { (std err) }\end{array}$ & $\begin{array}{l}\text { Timing } \\
\text { (std err) }\end{array}$ & $\mathrm{R}^{2}$ & $\begin{array}{r}\text { Constant } \\
\text { (std err) } \\
\end{array}$ & $\begin{array}{r}\text { Timing } \\
\text { (std err) }\end{array}$ & $\begin{array}{c}\text { Level } \\
\text { (std err) }\end{array}$ & $\mathrm{R}^{2}$ & $\begin{array}{l}\text { Constant } \\
\text { (std err) }\end{array}$ & $\begin{array}{r}\text { Timing } \\
\text { (std err) }\end{array}$ & $\begin{array}{c}\text { Level } \\
\text { (std err) }\end{array}$ & $\begin{array}{c}\text { Slope } \\
\text { (std err) }\end{array}$ & $\mathrm{R}^{2}$ \\
\hline 3-month & $\begin{array}{c}\mathbf{- 0 . 0 0 8} \\
(0.002)\end{array}$ & $\begin{array}{c}\mathbf{0 . 5 9 3} \\
(0.050)\end{array}$ & 0.88 & $\begin{array}{c}\mathbf{- 0 . 0 1 5} \\
(0.007)\end{array}$ & $\begin{array}{c}\mathbf{0 . 5 0 5} \\
(0.076)\end{array}$ & 0.19 & $\begin{array}{c}\mathbf{- 0 . 0 0 7} \\
(0.003)\end{array}$ & $\begin{array}{c}\mathbf{0 . 5 0 5} \\
(0.074)\end{array}$ & $\begin{array}{c}\mathbf{0 . 5 3 6} \\
(0.109)\end{array}$ & 0.89 & $\begin{array}{l}\mathbf{- 0 . 0 0 7} \\
(0.003)\end{array}$ & $\begin{array}{c}\mathbf{0 . 5 0 5} \\
(0.076)\end{array}$ & $\begin{array}{c}\mathbf{0 . 5 3 6} \\
(0.104)\end{array}$ & $\begin{array}{c}\mathbf{0 . 1 6 5} \\
(0.079)\end{array}$ & 0.90 \\
\hline 6-month & $\begin{array}{c}\mathbf{- 0 . 0 0 9} \\
(0.004)\end{array}$ & $\begin{array}{c}\mathbf{0 . 5 9 8} \\
(0.073)\end{array}$ & 0.71 & $\begin{array}{c}\mathbf{- 0 . 0 1 6} \\
(0.008)\end{array}$ & $\begin{array}{c}\mathbf{0 . 3 5 1} \\
(0.127)\end{array}$ & 0.06 & $\begin{array}{c}\mathbf{- 0 . 0 0 8} \\
(0.004)\end{array}$ & $\begin{array}{c}\mathbf{0 . 3 5 1} \\
(0.131)\end{array}$ & $\begin{array}{c}\mathbf{0 . 6 0 3} \\
(0.125)\end{array}$ & 0.76 & $\begin{array}{l}-0.008 \\
(0.004)\end{array}$ & $\begin{array}{c}\mathbf{0 . 3 5 1} \\
(0.127)\end{array}$ & $\begin{array}{c}\mathbf{0 . 6 0 3} \\
(0.121)\end{array}$ & $\begin{array}{c}\mathbf{0 . 3 7 7} \\
(0.154)\end{array}$ & 0.81 \\
\hline 2-year & $\begin{array}{c}0.008 \\
(0.007)\end{array}$ & $\begin{array}{c}\mathbf{0 . 5 5 0} \\
(0.087)\end{array}$ & 0.38 & $\begin{array}{c}-0.011 \\
(0.010)\end{array}$ & $\begin{array}{c}0.096 \\
(0.210)\end{array}$ & 0.00 & $\begin{array}{l}-0.002 \\
(0.007)\end{array}$ & $\begin{array}{c}0.096 \\
(0.219)\end{array}$ & $\begin{array}{c}\mathbf{0 . 6 4 3} \\
(0.125)\end{array}$ & 0.50 & $\begin{array}{c}-0.002 \\
(0.007)\end{array}$ & $\begin{array}{c}0.096 \\
(0.221)\end{array}$ & $\begin{array}{c}\mathbf{0 . 6 4 3} \\
(0.127)\end{array}$ & $\begin{array}{c}\mathbf{0 . 9 5 7} \\
(0.219)\end{array}$ & 0.69 \\
\hline 5-year & $\begin{array}{c}0.001 \\
(0.007)\end{array}$ & $\begin{array}{c}\mathbf{0 . 3 1 7} \\
(0.088)\end{array}$ & 0.17 & $\begin{array}{l}-0.003 \\
(0.008)\end{array}$ & $\begin{array}{l}-0.009 \\
(0.189)\end{array}$ & 0.00 & $\begin{array}{c}0.003 \\
(0.007)\end{array}$ & $\begin{array}{l}-0.009 \\
(0.182)\end{array}$ & $\begin{array}{c}\mathbf{0 . 3 9 7} \\
(0.122)\end{array}$ & 0.26 & $\begin{array}{c}0.002 \\
(0.007)\end{array}$ & $\begin{array}{l}-0.009 \\
(0.186)\end{array}$ & $\begin{array}{c}\mathbf{0 . 3 9 7} \\
(0.123)\end{array}$ & $\begin{array}{c}\mathbf{0 . 8 0 6} \\
(0.234)\end{array}$ & 0.45 \\
\hline 10-year & $\begin{array}{c}0.000 \\
(0.006)\end{array}$ & $\begin{array}{c}0.180 \\
(0.091)\end{array}$ & 0.10 & $\begin{array}{l}-0.003 \\
(0.006)\end{array}$ & $\begin{array}{c}0.021 \\
(0.149)\end{array}$ & 0.00 & $\begin{array}{c}0.001 \\
(0.006)\end{array}$ & $\begin{array}{c}0.021 \\
(0.144)\end{array}$ & $\begin{array}{c}0.215 \\
(0.122)\end{array}$ & 0.14 & $\begin{array}{c}0.001 \\
(0.006)\end{array}$ & $\begin{array}{c}0.021 \\
(0.143)\end{array}$ & $\begin{array}{c}0.215 \\
(0.114)\end{array}$ & $\begin{array}{c}\mathbf{0 . 6 0 0} \\
(0.211)\end{array}$ & 0.32 \\
\hline S\&P 500 & $\begin{array}{c}-\mathbf{0 . 1 5 6} \\
(0.065)\end{array}$ & $\begin{array}{l}-4.865 \\
(1.159)\end{array}$ & 0.36 & $\begin{array}{c}-0.093 \\
(0.086)\end{array}$ & $\begin{array}{c}-3.252 \\
(3.005)\end{array}$ & 0.03 & $\begin{array}{c}\mathbf{- 0 . 1 6 3} \\
(0.065)\end{array}$ & $\begin{array}{c}-3.252 \\
(3.033)\end{array}$ & $\begin{array}{c}-4.746 \\
(1.646)\end{array}$ & 0.38 & $\begin{array}{c}-0.163 \\
(0.067)\end{array}$ & $\begin{array}{c}-3.252 \\
(2.974)\end{array}$ & $\begin{array}{l}-4.746 \\
(1.694)\end{array}$ & $\begin{array}{c}-4.537 \\
(2.536)\end{array}$ & 0.43 \\
\hline
\end{tabular}

Notes. Number of observations is 58. Heteroskedasticity consistent standard errors are reported for $\mathrm{e}^{0}$ regressions. Bootstrap standard errors, as explained in text, are reported for regressions using timing and level. $\mathrm{R}^{2}$ statistics refer to OLS goodness-of-fit measures. Coefficients in bold are significant at 5\%. 
Figure 1

Expected Federal Funds Rates Based on Federal Funds Futures

- - August 13, 2002

- August 12, 2002

1.75

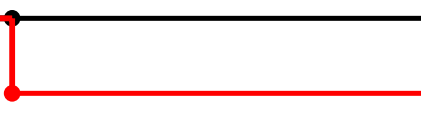

1.69

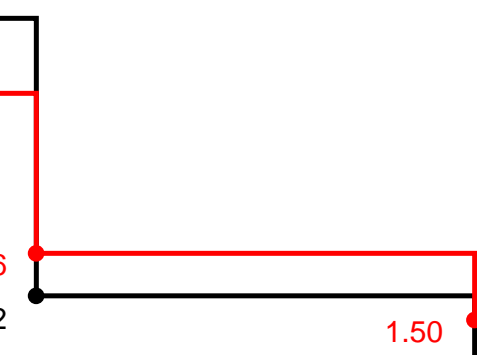

1.46

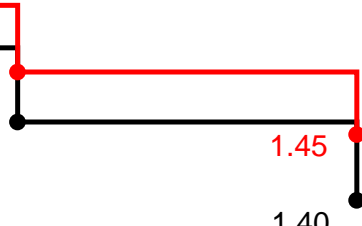

Percentage $7^{2.00}$

1.56

1.52 
Figure 2a

Current Policy Surprise $\left(e^{0}\right)$

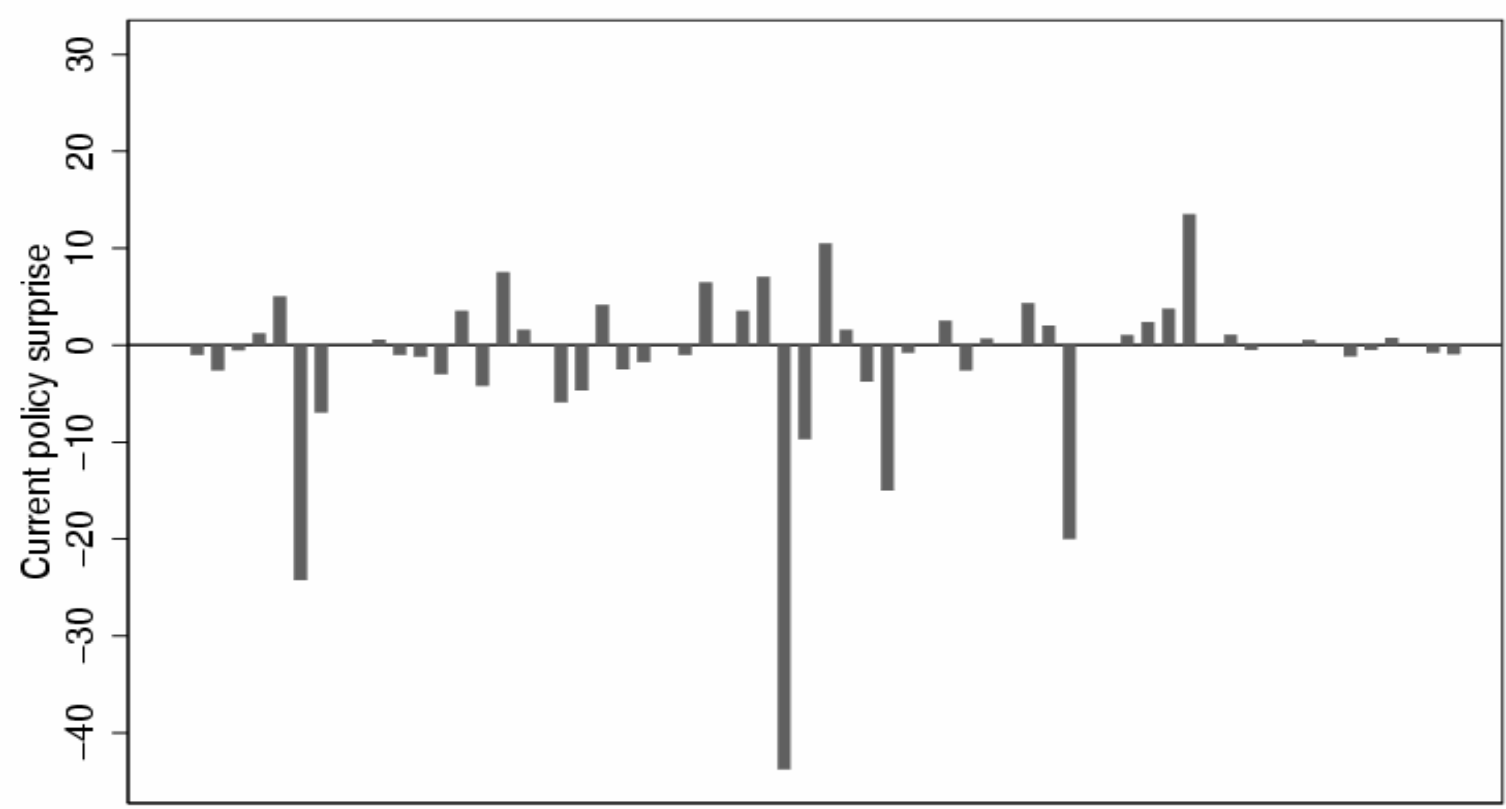

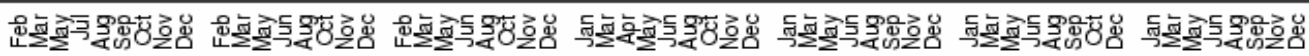
$\begin{array}{lllllll}1998 & 1999 & 2000 & 2001 & 2002 & 2003 & 2004\end{array}$

Figure 2b

Timing Surprise

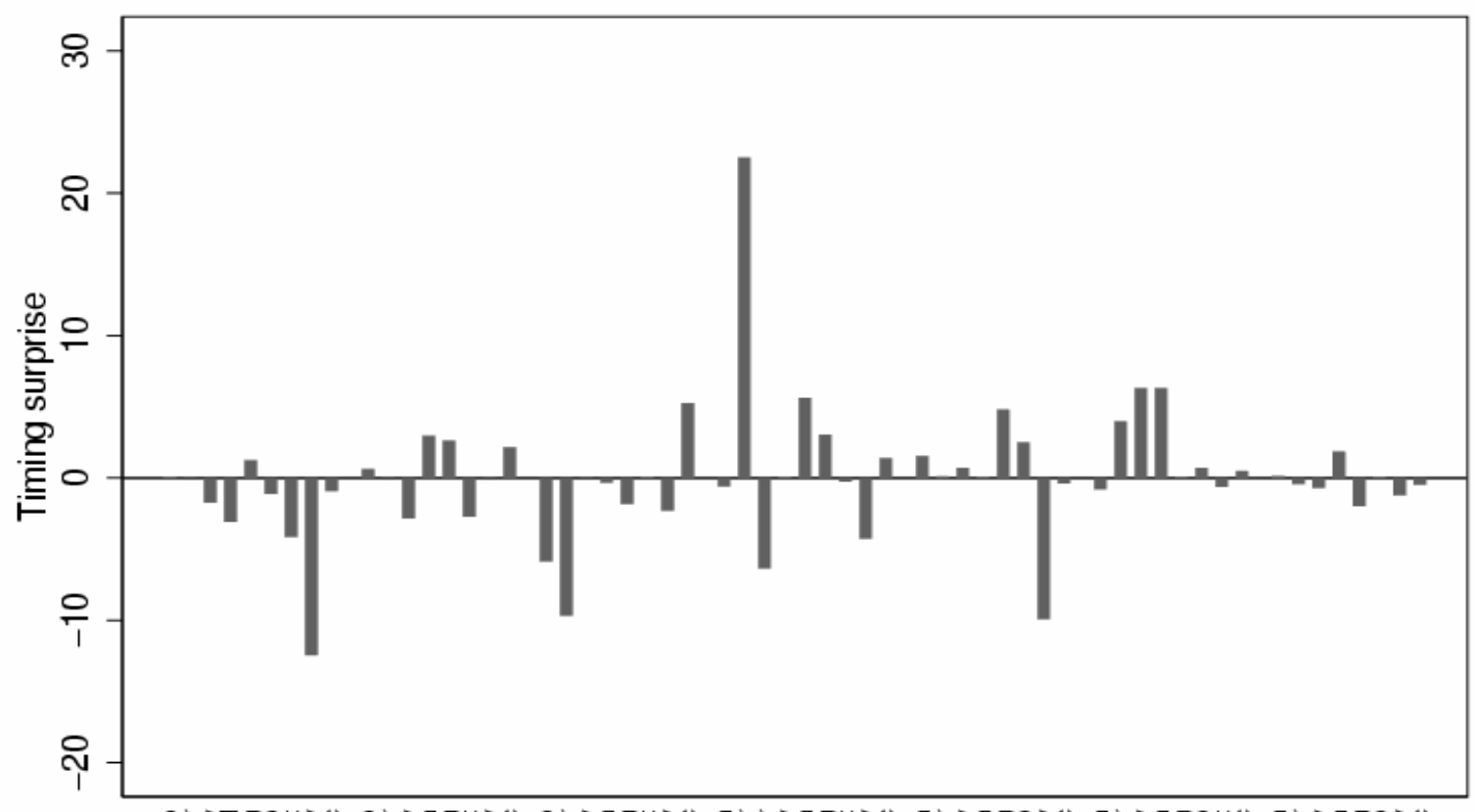

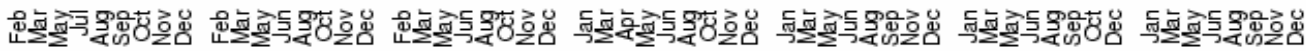

$\begin{array}{lllllll}1998 & 1999 & 2000 & 2001 & 2002 & 2003 & 2004\end{array}$ 
Figure 2c

Level Surprise

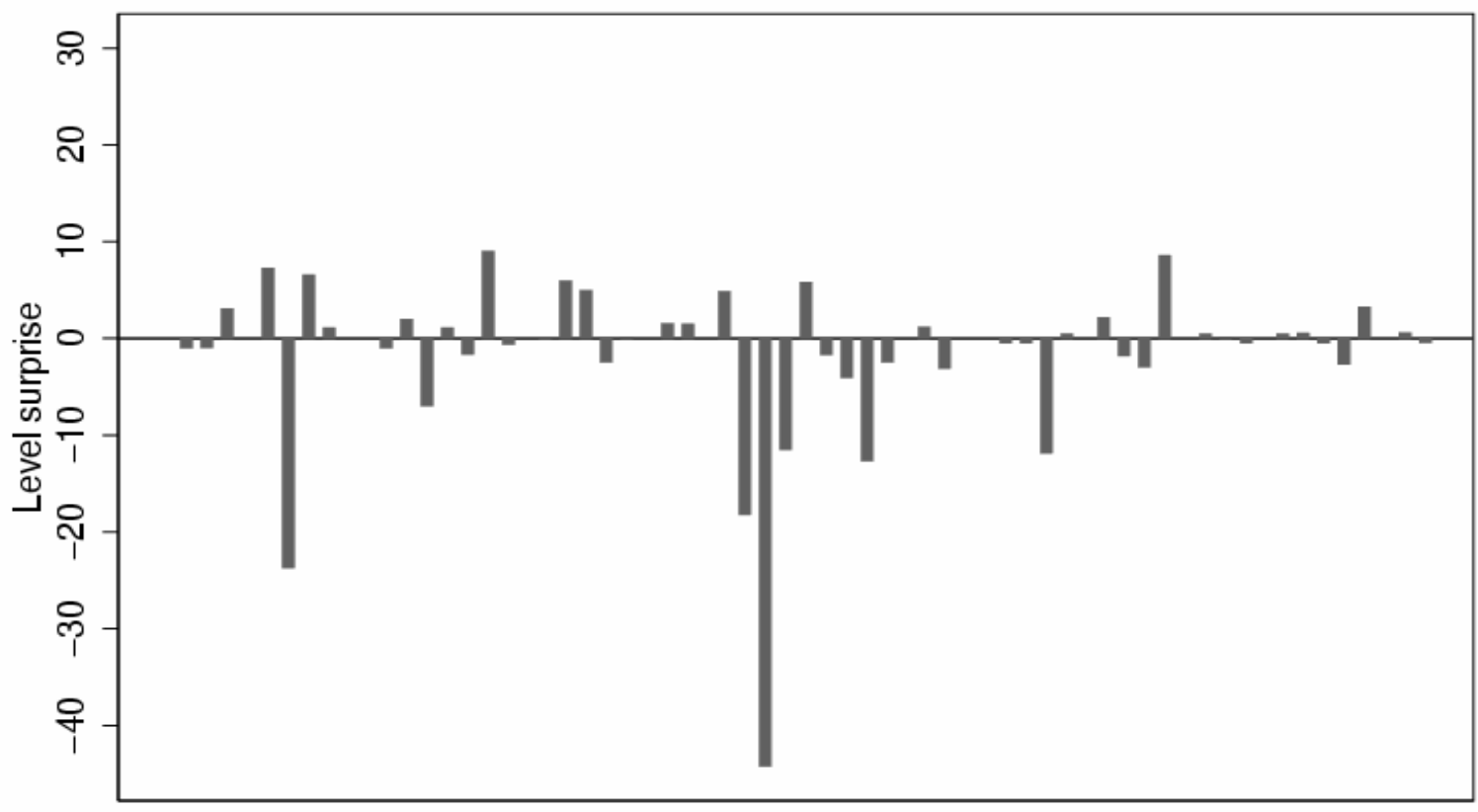

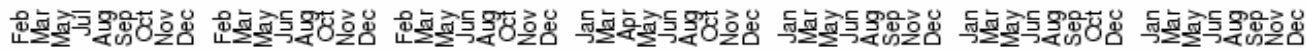
$\begin{array}{lllllll}1998 & 1999 & 2000 & 2001 & 2002 & 2003 & 2004\end{array}$

Figure 2d

Slope Surprise

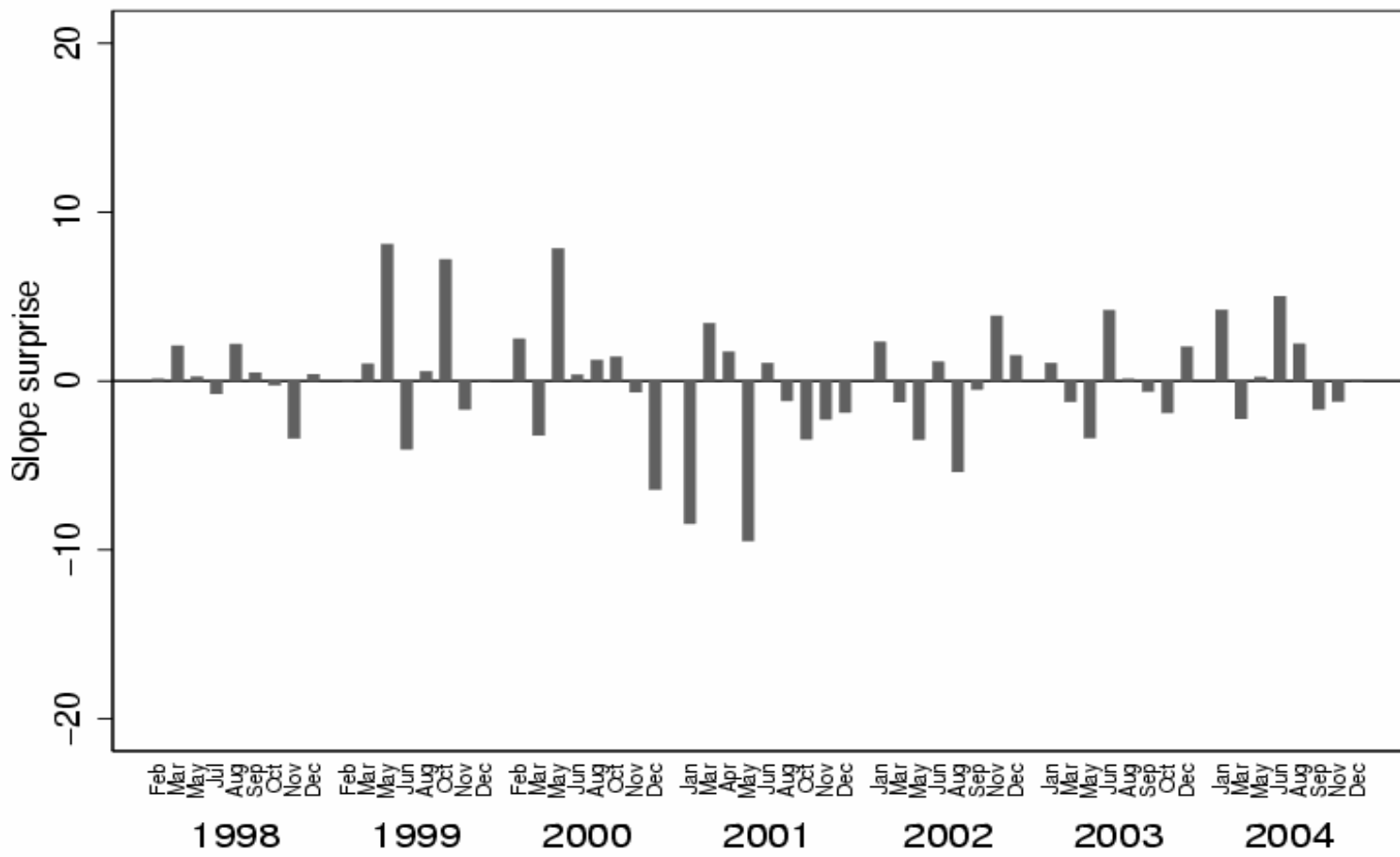

